\title{
Novel polymer matrix composite membrane doped with fumed silica particles for reverse osmosis desalination
}

\author{
Aneela Sabir ${ }^{\mathrm{a}, *}$, Atif Islam ${ }^{\mathrm{a}}$, Muhammad Shafiq ${ }^{\mathrm{a}}$, Amir Shafeeq ${ }^{\mathrm{b}}$, Muhammad Taqi Zahid Butt ${ }^{\mathrm{c}}$, \\ Nasir M. Ahmad ${ }^{\mathrm{d}}$, Khairuddin Sanaullah ${ }^{\mathrm{e}}$, Tahir Jamil ${ }^{\mathrm{a}}$ \\ a Department of Polymer Engineering and Technology, University of the Punjab, Lahore 54590, Pakistan \\ ${ }^{\mathrm{b}}$ Institute of Chemical Engineering and Technology (ICET), University of the Punjab, Lahore 54590, Pakistan \\ c Faculty of Engineering and Technology, University of the Punjab, Lahore 54590, Pakistan \\ d School of Chemical and Materials Engineering (SCME), National University of Sciences and Technology (NUST), H-12 Islamabad, Pakistan \\ e Department of Chemical Engineering and Energy Sustainability, Faculty of Engineering, Universiti Malaysia Sarawak (UNIMAS), 94300 Kota Samarahan, Sarawak, Malaysia
}

\section{H I G H L I G H T S}

- Doping of FSP in polymer matrix membrane; involving dissolution casting methodology

- FSP is used as an additive to inflate salt rejection properties.

- Mechanical properties augmented for PMCM

- Uniform dispersion of FSP on PMCM posing dense structure observed in SEM micrographs

\section{A R T I C L E I N F O}

\section{Article history:}

Received 22 July 2014

Received in revised form 25 December 2014

Accepted 28 December 2014

Available online 3 January 2015

\section{Keywords:}

Polymer matrix composite membrane

Fumed silica particles

Reverse osmosis

Desalination

\begin{abstract}
A B S T R A C T
Novel polymer matrix composite membranes of cellulose acetate (CA)/polyethylene glycol (PEG) doped with 10-30 wt.\% fumed silica particles (FSP) were synthesized. The dissolution casting methodology was used to construct reverse osmosis (RO) membrane which accounts the explicit application for desalination process. The interactions between polymer chains and doped FSP were confirmed by Fourier transform infrared spectroscopy (FTIR). Differential scanning calorimetry thermograms support the physical nature of polymer matrix composite membranes (PMCMs) and an improved glass transition temperature $\left(T_{g}\right)$ from 78.3 to $92.4^{\circ} \mathrm{C}$ was observed. The thermal stability of the composite membranes significantly enhanced with the addition of FSP. The typical morphology of PMCM was observed using scanning electron microscopy (SEM) and atomic force microscopy (AFM). The 30 wt.\% of FSP filled PMCM showed substantial improvement in tensile strength (8.2 MPa) and Young's modulus (854.0 MPa) as compared to the PMCM without FSP. The percentage water content (WC) of the membrane doped with 30 wt.\% FSP absorbed more water as compared to the other membranes. It was also noticed that the FSP doped PMCM enhanced the desalination process which was monitored in terms of permeation flux $\left(\mathrm{L} / \mathrm{m}^{2} \cdot \mathrm{h}\right)$ and salt rejection (\%). The optimum performance of desalination process was shown by $30 \mathrm{wt} . \%$ FSP doped PMCM; the permeation flux was $0.66 \mathrm{~L} / \mathrm{m}^{2} \cdot \mathrm{h}$ and salt rejection was $98.4 \%$ for the initial feed of $0.35 \mathrm{wt} . \% \mathrm{NaCl}$ aqueous solution at $25^{\circ} \mathrm{C}$ and operating pressure of $4.0 \mathrm{bar}$ (osmotic pressure $2.9 \mathrm{bar}$ ).
\end{abstract}

(c) 2014 Elsevier B.V. All rights reserved.

\section{Introduction}

The water scarcity around the world has become an inescapable issue because of the negligence in wastewater management and exponential growth in world population [1,2]. Seawater desalination is considered to be an adequate and sustainable solution for the supply of water to deal with enormous issue of supply and demand of purified

\footnotetext{
* Corresponding author.

E-mail address: aneela.pet.ceet@pu.edu.pk (A. Sabir).
}

drinking water [3]. Desalination process is the removal of salts from brackish, saline and seawater by RO process, which is today the leading technology to convert salt water into clean water for human consumption, industrial and agriculture applications [4,5]. RO membrane separation process is the most promising tool for saline water treatment and has overtaken the conventional thermal processes like multistage flashing (MSF), multieffect distillation (MED) and electrodialysis [5-7]. RO technology requires less energy and endures a great potential for solving and consistently alleviating the most pervasive problem of water scarcity. Desalination process by RO has become a viable solution with 